Research Article

\title{
Shaking Table Test of High Pier and Small Radius Curved Bridge under Multi-point Excitation
}

\author{
Lei Yan $\left(D,{ }^{1,2}\right.$ Guo Li, ${ }^{2}$ Kang An, ${ }^{2}$ Kefeng Yue, ${ }^{1}$ and Zhi Lin ${ }^{1}$ \\ ${ }^{1}$ State Key Laboratory of Mountain Bridge and Tunnel Engineering, Chongqing Jiaotong University, Chongqing 400074, China \\ ${ }^{2}$ School of Civil Engineering, Chongqing Three Gorges University, Chongqing 404100, China \\ Correspondence should be addressed to Lei Yan; yanlei1988413@163.com
}

Received 31 December 2020; Revised 12 April 2021; Accepted 30 April 2021; Published 13 May 2021

Academic Editor: Zhigang Zhang

Copyright (C) 2021 Lei Yan et al. This is an open access article distributed under the Creative Commons Attribution License, which permits unrestricted use, distribution, and reproduction in any medium, provided the original work is properly cited.

The non-uniform stratum and uneven surface have the complicated seismic spatial variability. The seismic response of high pier and small radius curved bridge caused by the seismic specificity of this kind of terrain has not been systematically studied. According to the multi-point excitation theory of long-span structures and the similar theory of shaking table test in model structures, a high pier with small radius curved girder bridge was used as the research object. The shaking table test of real bridge model was carried out to study the seismic response laws of this kind of bridge under multi-point excitation. The results show that the designed seismic wave expansion device can meet the test requirements. The frequency of the model structure decreases rapidly and the damping ratio increases during the whole test process. The local terrain effect amplifies the seismic response of high pier and small radius curved bridge. The seismic response of high pier and small radius curved bridge is affected by different frequency spectrum seismic waves, and there is a big difference. Based on the above results, the impact of multi-point excitation should be considered in seismic design of high pier with small radius curved bridge.

\section{Introduction}

High pier and small radius curves bridge has the advantages of strong terrain adaptability and less restrictions by the surrounding environment and traffic routes. Therefore, it can better achieve traffic interconnection in all directions, ensure smooth traffic routes, and improve urban traffic tension. At present, with the development of material properties and construction technology, curved bridges are developing towards higher and larger spans. However, the load on a curved bridge during an earthquake is actually a movement of the support over time. For structures with large spatial distribution, the ground motions at different points in the structural scale range during the same earthquake are different, and the amplitudes of the seismic waves at each pier may be different, and even the wave forms may vary. As a result, it caused high pier bridge with small radius curves to have the significant bending and torsional coupling effects and complex internal force distribution.
Therefore, it is necessary to carry out multi-point incentive research for this kind of bridge.

Cheng et al. [1] conducted a shaking table test of the scale model of the bridge based on a prototype of an interchange bridge damaged in the San Fernando earthquake. The seismic performance and the dynamic response of the structure at the expansion joint were studied. Fan [2] conducted long-term monitoring and tests on a curved bridge to study structural frequency changes and structural torsion effects. Gomez et al. [3] analyzed the influence of the input mode of ground motion, the restraint form of pier and beam, and the change of span on the seismic response of the small radius curve bridge. Yan et al. [4-6] carried out shaking table tests on various forms of curved bridges, studied the damage and failure modes of curved bridges under earthquake, and discussed the pounding response law of curved bridges under earthquake. The literature $[7,8]$ studied the influence of local irregular topography on ground motion when Rayleigh waves propagate and pointed 
out that Rayleigh waves have a significant amplification effect on solitary process topography. It is clearly pointed out in [9] that the seismic excitation received at the supporting point of a long-span structure within $50 \mathrm{~m}$ may be quite different.

Zhang et al. [10] conducted a shaking table test on a bridge with a small radius curve considering the dynamic interaction between pile-soil and bridge structure, obtained the vibration response law of pile-soil and structure system, and discussed the failure characteristics and failure modes of the bridge. Lupoi et al. [11] conducted theoretical and experimental studies on the seismic response of long-span bridge structures under multi-point excitation and the results show that the seismic response of long-span bridge structures is closely related to the input mode of seismic waves and the site characteristics of the bridge supporting points. Wang et al. $[12,13]$ conducted a shaking table test on a long-span continuous rigid frame bridge and studied the seismic response law of the bridge structure under local site effect and multi-point excitation. Liu et al. [14, 15] studied the multi-point excitation failure mode of bridges across V-shaped canyons, explored the impact of spatial effects of ground motions on structures in rough terrain, and analyzed the influential factors of the frequency characteristics of ground motions in such terrains in detail. Xie et al. [16] carried out the shaking table test of multi-point excitation on the whole model of pile-soil-bridge and studied the influence of multi-point excitation on the seismic response of the structure.

In summary, researchers have carried out some theoretical and experimental studies on the influence of the seismic response of bridge under multi-point excitation, but it is rare to study the dynamic response laws of high pier bridge with small radius curves considering the local site effect. Based on this, a 1/20 scale ratio high pier bridge with small radius curves test model has been designed and produced. Combined with the basic principles of structural dynamics, a seismic wave expansion device to achieve multipoint excitation in a single shaking table test has been designed and manufactured, and it was used to complete the shaking table test for a high pier and small radius curved bridge under multi-point excitation. The dynamic characteristics of high pier and small radius curved bridge under multi-point excitation, the relationship between seismic intensity, dynamic change factor and pier displacement response, the influence of local terrain effect on the overall response of curved bridge structure, and the law of pier strain response are studied in this paper. Through the study of this paper, it is expected to provide some theoretical reference for the seismic design theory of high pier and small radius curve bridge structure and related code research.

\section{Research on Multi-Point Excitation Theory}

Due to the different site and soil conditions where the bridge foundation is located, the characteristics of the seismic wave when it reaches each pier foundation are different in the actual vibration process of the bridge. Therefore, when analyzing the seismic response of long-span bridge structure, we should consider the influence of local terrain effect on the dynamic response of the structure caused by the input seismic wave excitation difference at each support point especially.

In this paper, the dynamic change factor $a$ is defined to represent the change degree of local topographic effect on seismic amplitude. The value of this factor is related to the site characteristics and complexity of the structure. The motion equation of the structure under multi-point excitation is as follows [6]:

$$
\begin{gathered}
{\left[\begin{array}{cc}
M_{j j} & M_{j z} \\
M_{z j} & M_{z z}
\end{array}\right]\left\{\begin{array}{c}
\ddot{X}_{j} \\
\ddot{X}_{z}
\end{array}\right\}+\left[\begin{array}{ll}
C_{j j} & C_{j z} \\
C_{z j} & C_{z z}
\end{array}\right]\left\{\begin{array}{c}
\dot{X}_{j} \\
\dot{X}_{z}
\end{array}\right\}} \\
+\left[\begin{array}{ll}
K_{j j} & K_{j z} \\
K_{z j} & K_{z z}
\end{array}\right]\left\{\begin{array}{c}
X_{j} \\
X_{z}
\end{array}\right\}=\left\{\begin{array}{c}
0 \\
P_{z}
\end{array}\right\},
\end{gathered}
$$

where the lower corner marks $j$ and $z$ represent the superstructure node and support node of the bridge, respectively. $X, \dot{X}$, and $\ddot{X}$ are the absolute displacement, absolute velocity, and absolute acceleration vectors of each node of the bridge structure under seismic excitation respectively. $M$, $C$, and $K$ are the mass matrix, damping matrix, and stiffness matrix of the bridge structure respectively. $P_{z}$ is the seismic input load vector by the support node, which should include the seismic load of different supports.

In order to facilitate internal force analysis of the structure, displacements of each node of the structure are decomposed as

$$
\left\{\begin{array}{c}
X_{j} \\
X_{z}
\end{array}\right\}=\left\{\begin{array}{c}
X_{j}^{s} \\
X_{z}^{s}
\end{array}\right\}+\left\{\begin{array}{c}
X_{j}^{d} \\
0
\end{array}\right\},
$$

where $X_{j}^{s}$ is the quasi-static displacement caused by the displacement of the bearing joint and $X_{j}^{d}$ is the quasi-dynamic displacement caused by the acceleration of the bearing. Ignoring all the dynamic terms, the first line of equation (1) can be expanded as

$$
K_{j j} X_{j}^{s}+K_{j z} X_{z}^{s}=0 .
$$

After changing equation (3), we can get

$$
X_{j}^{s}=-K_{j j}^{-1} K_{j z} X_{z}^{s}
$$

where $\gamma=K_{j j}^{-1} K_{j z}$ is called quasi-static modal matrix, which represents the displacement of the superstructure caused by static displacement of the support.

It is assumed that the damping force of the structure is only related to the relative velocity of the structure, and $M_{j z}=0$ when centralized mass models. Substituting equation (5) into equation (2), the first line is expanded into

$$
M_{j j} \ddot{X}_{j}^{d}+C_{j j} \dot{X}_{j}^{d}+K_{j j} X_{j}^{d}=-M_{j j} \gamma \ddot{X}_{z} .
$$

The above formula is the dynamic equation of the bridge structure under the condition of multi-point excitation.

\section{Experimental Design}

3.1. Design of Multi-Point Excitation Expansion Device with Single Shaking Table Test. To carry out non-uniform excitation test for irregular curved bridges due to their 
complicated stress and significant coupling effect of bending and torsion is necessary. It has been pointed out that the multi-point excitation analysis of seismic response should be considered when the bridge structure has many spans and long spans, uneven distribution of longitudinal mass, stiffness and linear shape of the bridge, large difference of adjacent pier height, large central angle and skew angle of curved bridge and inclined bridge, and irregular bridge with isolation bearing and damper.

In this paper, based on the basic principle of structural dynamics and considering the requirements of actual test, an expansion device for realizing multi-point excitation with a single vibration table is made through theoretical analysis. The basic theory has been related to theoretical derivation in literature [5], which will not be repeated here. The device is composed of Q345 channel steel, angle steel, HRB335 steel bars with a diameter of $22 \mathrm{~mm}$, high-strength bolts, steel plates, and universal wheels, etc. The design diagram and physical model of the extension device are shown in Figure 1.

3.2. Similarity Ratio of Model. According to the bearing capacity and geometric size of the shaking table, as well as the limited conditions such as test site, the geometric similarity ratio of the model is $1 / 20$. Considering the effect of model gravity acceleration, the output capacity of shaking table, and the realization of artificial counterweight, the model acceleration similarity ratio is 2.5 . In addition, the elastic modulus similarity ratio of the model concrete and steel is 0.64 , and the remaining similarity ratio is derived from the three above basic similarity ratios. The similarity ratio of the experimental model is shown in Table 1.

3.3. Design of the Experimental Model. The shaking table test model for this experimental is a reinforced concrete high pier and small radius curved bridge with a scale ratio of $1: 20$. The example curved bridge is composed of circular curve +transition curve + transition curve + circular curve, and the length of each section is $18.65 \mathrm{~m}+20 \mathrm{~m}+20 \mathrm{~m}+18.65 \mathrm{~m}$, respectively. The span combination is $2 \times 35.7 \mathrm{~m}$, the straight line length of the bridge is $71.4 \mathrm{~m}$, the curve length is $77.3 \mathrm{~m}$, and the pier height is $30 \mathrm{~m}$. Part of the structure is a box girder with equal cross section, the pier is a rectangular single pier section, and the bottom and top of the pier are provided with $2.5 \mathrm{~m}$ solid sections. The layout of the model is shown in Figure 2. The main girder of the model is an equal-section with single-box and single-chamber box girder, the girder height is $10 \mathrm{~cm}$, and the wall thickness of box girder is $2.5 \mathrm{~cm}$. The model bridge has hollow pier, and the height of pier is $155 \mathrm{~cm}$. The high of solid section is $23 \mathrm{~cm}$ set at the top and bottom of the pier, and the wall of the hollow section is $5 \mathrm{~cm}$. In order to meet with the anti-overturning demand of the irregular curved bridge, two anti-torsion supports were set at the top of the three piers, which were directly placed between the piers and the box girder.

In shaking table test, the accuracy and visibility of test results are directly affected by the correctness of model material selection. The bridge span is $2 \times 35.7 \mathrm{~m}$, bridge straight line length is $71.4 \mathrm{~m}$, and the curve length is $77.3 \mathrm{~m}$, with $30 \mathrm{~m}$ high pier, the upper structure of cross section of box girder, such as piers for rectangular single pier cross section, with $2.5 \mathrm{~m}$ solid pier top and bottom section. The longitudinal reinforcement of model pier and girder is HRB335 ribbed bar with diameter of $6 \mathrm{~mm}$, and the stirrup is HPB300 plain round bar with diameter of $6 \mathrm{~mm}$. The spacing of stirrups was designed as $6 \mathrm{~cm}$. The reinforcement skeleton of piers and girder is shown in Figures 2 and 3. The ceramsite concrete was used to simulate the concrete of actual structure, and the test parameter of particle concrete is shown in Figure 3. According to the test results, the elastic modulus of ceramsite concrete is $2.2 \mathrm{e}^{4} \mathrm{~N} / \mathrm{mm}^{2}$ and the strength grade is $\mathrm{C} 25$, which meets the test requirements.

3.4. Selection of Seismic Waves. Imperial Valley wave (IVE) of class I site, El-Centro (ELC) and Lanzhou (LZ) seismic wave of class II site, and Taft wave of class III site were all selected for this test. The seismic wave excitation load is divided into six levels, and the peak acceleration of each level of seismic wave is $125 \mathrm{gal}, 250 \mathrm{gal}, 375 \mathrm{gal}, 500 \mathrm{gal}$, 750 gal, and 1000 gal, respectively. During the loading process, according to the principle of peak acceleration from small to large, i.e., after loading 4 seismic waves under the peak acceleration of a certain level, the first-order frequency measurement of the structure is carried out, and then the next level seismic wave record is loaded. The stiffness of high pier and small radius curved beam bridge structure is weak in the direction of the connecting line of the head and tail piers, so more failure modes are likely to occur along the direction of seismic excitation. Based on this, the input direction of seismic wave in this experiment is the connection direction of the head and tail piers of curved bridge.

3.5. Layout of Measuring Points. The purpose of this test is to study the influence of multi-point excitation on the seismic response of curved bridge with high pier and small radius by measuring the dynamic response of points. During the test, the acceleration, displacement, and strain responses for the measuring points of the model were installed at the key position. Three types of sensors were installed at the key positions of the bridge model.

(1) 8 acceleration sensors (PCB type series 380 GFB3G/ $30 \mathrm{AY}$ ) were distributed in the shake table, girders, and top of piers to measure the vertical, longitudinal, and transverse acceleration, respectively.

(2) 6 displacement sensors (891-II) were distributed in the shake table and top of piers to measure longitudinal and transverse displacement.

(3) 24 strain gauges were distributed in steel bar at the bottom of the piers.

\section{Result Analysis}

4.1. Analysis of Structural Frequency and Damping Ratio. In the experiment, when the loading of each seismic wave was completed, the natural vibration characteristics of the 


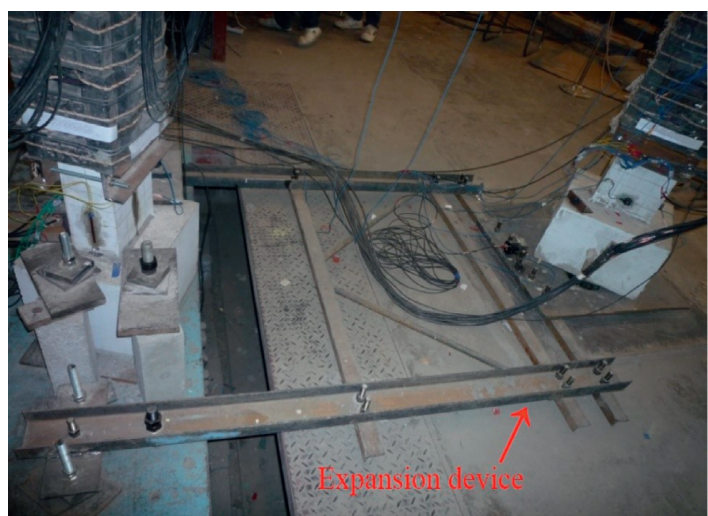

(a)

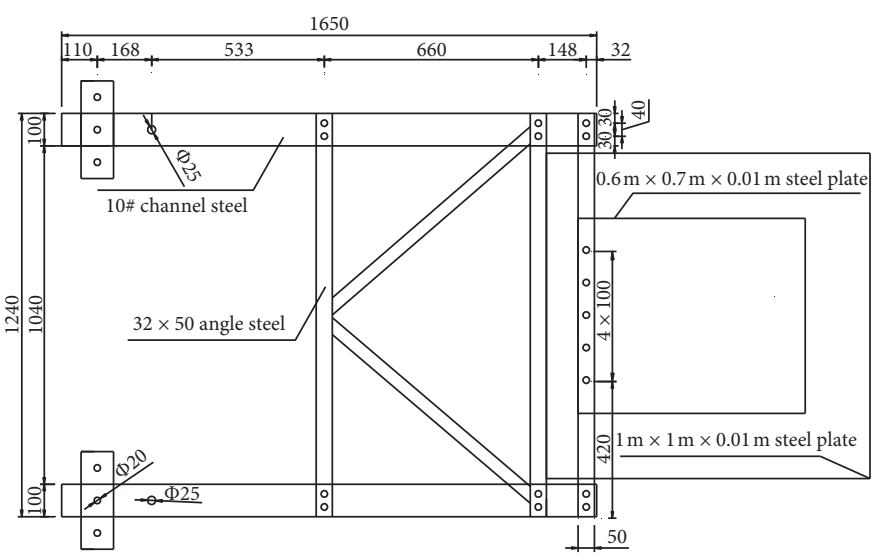

(b)

Figure 1: The expansion device. (a) The physical diagram of expansion device. (b) The design diagram of expansion device.

TABle 1: Similar constants.

\begin{tabular}{|c|c|c|c|c|}
\hline Properties & Physical quantity & Dimension & Similitude function & Similitude parameter \\
\hline \multirow[t]{3}{*}{ Geometric } & Length & (L) & $S_{l}$ & $1 / 20$ \\
\hline & Elastic modulus & $(\mathrm{FL})^{-2}$ & $S_{E}$ & $1 / 1.57$ \\
\hline & Strain & - & $S_{\sigma} / S_{E}$ & 1 \\
\hline \multirow[t]{3}{*}{ Material properties } & Stress & $(\mathrm{FL})^{-2}$ & $S_{\sigma}=S_{E}$ & $1 / 1.57$ \\
\hline & Mass & $(\mathrm{F} / \mathrm{LT})^{-2}$ & $S_{\sigma} S_{l}^{2} / S_{a}$ & $1 / 1570$ \\
\hline & Density & $(\mathrm{FL})^{-3}$ & $S_{\sigma} /\left(S_{a} S_{l}\right)$ & 5.10 \\
\hline Load performance & The force & $(\mathrm{FL})^{-2}$ & $S_{\sigma} S_{l}^{2}$ & $1 / 628$ \\
\hline \multirow{2}{*}{ Dynamic properties } & Time & $(\mathrm{T})$ & $S_{l}^{0.5} S_{a}^{-0.5}$ & $1 / 7.07$ \\
\hline & Acceleration & $(\mathrm{LT})^{-2}$ & $S_{a}^{a}$ & 2.5 \\
\hline
\end{tabular}

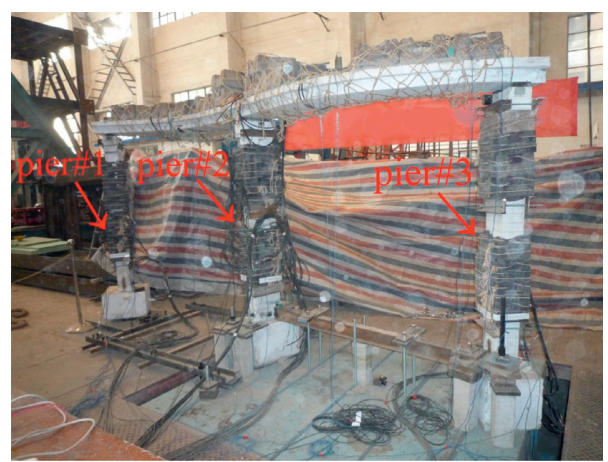

Figure 2: Experimental model.

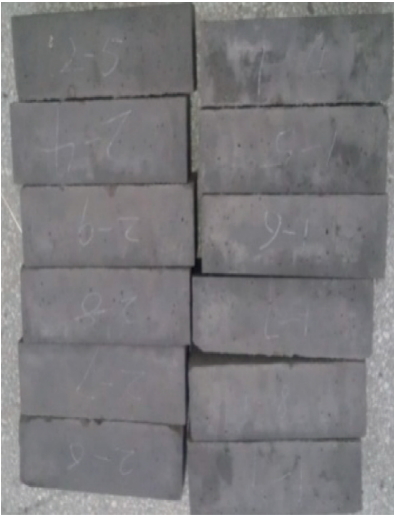

(a)

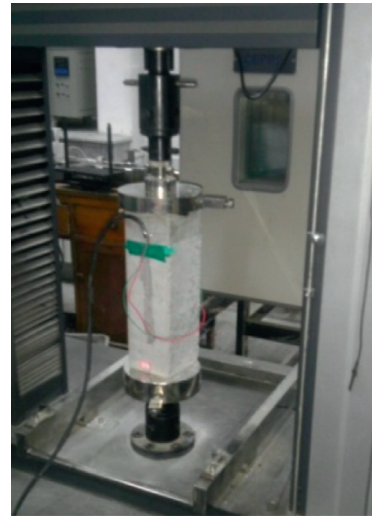

(b)

Figure 3: The test parameter of concrete material characteristic. (a) Test block. (b) Material property test. 
model structure are tested. The fundamental frequency and damping ratio of the structure were calculated according to the structural dynamics formula, and it is shown in Figure 4.

From Figure 4, the first-order frequency of structure decreases rapidly under the action of lower level earthquake excitation. With the increase of load, the first-order frequency of the structure decreases slowly and the damping ratio increases. There are two reasons for the above results. On the one hand, because of some cracks and other damage in the structure of the model bridge during the vibration process, the stiffness of the model structure decreases, so the frequency of the model structure decreases. On the other hand, with the increase of the peak value of seismic wave input, the rubber bearing will slide on the top of the pier and the bearing will be destroyed, which will change the boundary conditions of the bridge structure, and the stiffness of the model structure will also decline seriously, which will also lead to the decrease of the frequency of the model bridge. The fundamental frequency of the structure in the final state is 2.40 times that of the initial state, and the damping ratio is 7.35 times that of the initial structure.

4.2. Analysis of the Effect of Multi-Point Excitation by the Expansion Device. In order to realize the research purpose of multi-point excitation on a single shaking table, an expansion device of shaking table was designed to effectively control the input seismic waves at the bridge foundation. After each input seismic wave, the acceleration time history curve of the shaking table and the S3 pier foundation on the expansion device was compared. Due to the length of the article, Figure 5 only shows the comparison between IVE wave and ELC Earthquake wave, when the input peak value of local seismic wave is $500 \mathrm{gal}$. Table 2 shows the dynamic change factor of the expansion device under different site types and different acceleration peaks.

From the analysis of Figure 5 and Table 2, the dynamic change factor of the expansion device is 1.27-1.82 when the IVE wave was input, 1.18-1.62 when the ELC wave was input, 1.26-1.36 when the LZ wave was input, and 1.36-1.56 when the TAFT wave was input. Therefore, the designed expansion device has a certain change in the seismic wave input to the shaking table, and it is completely feasible to use it to realize non-uniform seismic wave input at different support points with a single shaking table.

\subsection{Analysis of Local Terrain Effect on Seismic Response of} Bridge. In order to study the effect of amplification of seismic amplitude caused by local terrain effect on seismic response of high pier and small radius curves bridge, Table 3 shows the peak acceleration and displacement response of each pier when the El-Centro earthquake wave with peak acceleration of 500 gal was input and the dynamic change factor was 1.62 .

From Table 3, the maximum displacement response of the bridge pier is the tangential displacement of pier 3\#, reaching $20.365 \mathrm{~mm}$. The minimum displacement is the radial displacement of pier 2\#, with a value of $7.167 \mathrm{~mm}$. The peak acceleration and displacement at the top of pier $1 \#$ and pier 2\# in radial are less than tangential, and the radial peak acceleration and displacement at the top of pier $3 \#$ are greater than tangential. The above results are determined by the placement of each pier. The resultant response and acceleration response of pier 3\# are larger than pier $1 \#$ and pier 2\#, and the reason is that the input at the bottom of pier $3 \#$ is caused by the amplification of local terrain effect on seismic excitation when $a$ (dynamic change factor) is 1.6.

4.4. Analysis of the Displacement Response of Pier 3\#. In order to study the correspondence between the model bridge structure dynamic response and the seismic wave input acceleration peak, as well as dynamic change factor, Figure 6 shows the correspondence between the displacement response at the top of the pier 3\# and the peak acceleration of the seismic wave input. Figure 7 shows the relationship between the displacement response at the top of the pier 3\# and dynamic change factor.

From Figure 6, the radial and tangential displacement of pier 3\# increase with the increase of the input acceleration peak value of seismic wave. Under the action of the four seismic waves, LZ wave makes the dynamic response generated by the structure more significant. Even with the same acceleration peak input, seismic waves at different sites will make the different dynamic response of the structure. Therefore, the structural dynamic response of different site types should be taken as the research object in the structural design. From the analysis in Figure 7, the dynamic change factor is an important factor affecting the dynamic response of pier 3\#; that is to say, the multi-point excitation will have a greater impact on the dynamic response of the structure. Therefore, when designing irregular bridges, the transmission of seismic waves in different sites should be considered to lead to the change of the dynamic response of the structure.

From Figure 7, the radial displacement of pier 3\# is larger than the tangential displacement, except for some cases. It can be seen from the analysis of the input direction of seismic wave that the angle between the input direction of seismic wave and the tangential direction of pier $3 \#$ is 45 degrees, so the radial and tangential displacement of pier \#3 bridge pier should be basically equivalent; however, the test results are different from this.

According to the analysis of the spatial layout characteristics of the model curved bridge, it is known that the displacement response of the top of pier 3\# is not only related to the input direction of the seismic wave excitation, but also related to the curve of the girder and the section characteristics of the pier 3\#. Under the action of seismic force, there is a tendency of torsional motion to girder, which causes the girder to undergo torsional motion vibration, so that the radial displacement is larger than the tangential displacement at the top of the bridge pier 3\#.

4.5. Analysis of the Strain Response of Bridge. After each devastating earthquake, the more typical earthquake damage is the phenomenon that the damage to the bottom of the pier 


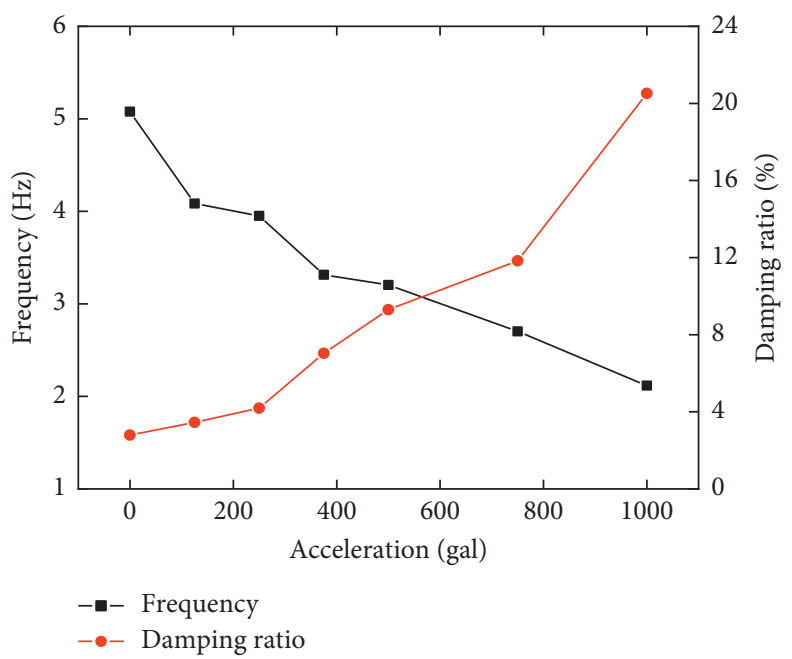

Figure 4: The change of fundamental frequency and damping ratio.

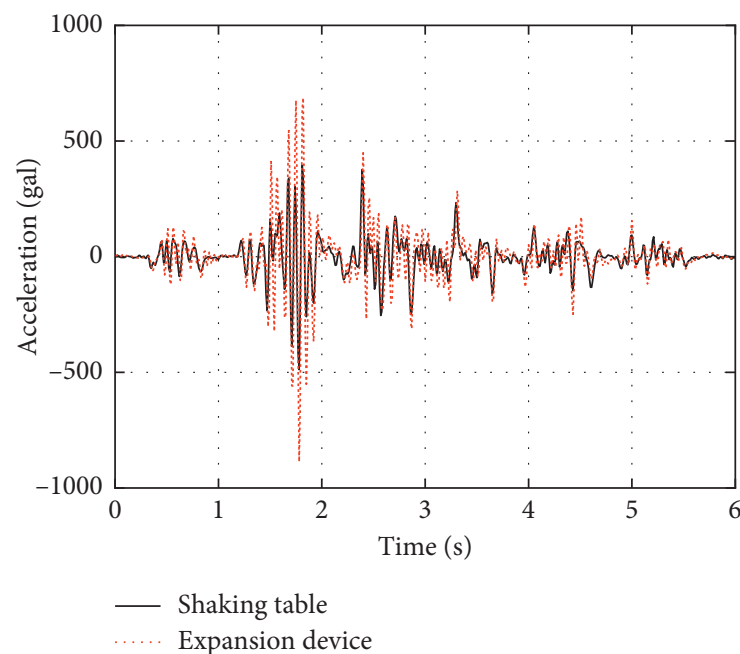

(a)

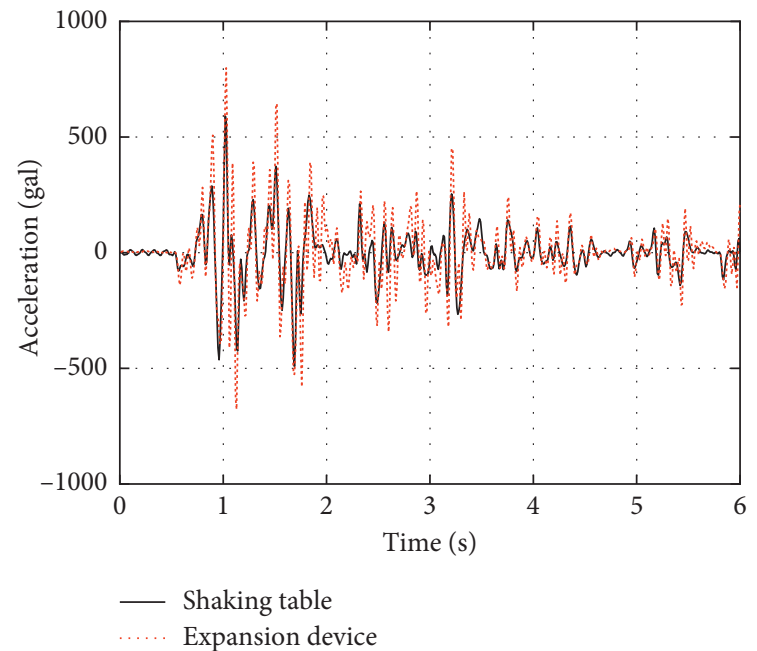

(b)

FIgURE 5: The comparison time history curves between shaking table and expansion device. (a) IVE-500. (b) ELC-500.

TABLE 2: The comparison peak acceleration between shaking table and expansion device.

\begin{tabular}{|c|c|c|c|c|c|c|c|c|c|c|c|c|c|}
\hline \multirow{2}{*}{$\begin{array}{c}\text { Seismic wave } \\
\text { Location }\end{array}$} & & \multicolumn{3}{|c|}{ IVE } & \multicolumn{3}{|c|}{ ELC } & \multicolumn{3}{|c|}{$\mathrm{LZ}$} & \multicolumn{3}{|c|}{ TAFT } \\
\hline & & $S$ & $\mathrm{C}$ & $\mathrm{C} / \mathrm{S}$ & $S$ & $\mathrm{C}$ & $\mathrm{C} / \mathrm{S}$ & S & $\mathrm{C}$ & $\mathrm{C} / \mathrm{S}$ & $\mathrm{S}$ & $\mathrm{C}$ & $\mathrm{C} / \mathrm{S}$ \\
\hline \multirow{6}{*}{ Input peak acceleration (gal) } & 125 & 133 & 200 & 1.50 & 121 & 168 & 1.39 & 123 & 156 & 1.27 & 124 & 169 & 1.36 \\
\hline & 250 & 256 & 389 & 1.52 & 238 & 335 & 1.41 & 249 & 332 & 1.33 & 233 & 321 & 1.38 \\
\hline & 375 & 370 & 600 & 1.62 & 365 & 481 & 1.32 & 378 & 485 & 1.28 & 359 & 561 & 1.56 \\
\hline & 500 & 487 & 886 & 1.82 & 492 & 799 & 1.62 & 515 & 699 & 1.36 & 479 & 684 & 1.43 \\
\hline & 750 & 758 & 998 & 1.32 & 721 & 981 & 1.36 & 742 & 934 & 1.26 & 731 & 1001 & 1.37 \\
\hline & 1000 & 988 & 1257 & 1.27 & 1006 & 1198 & 1.19 & 968 & 1244 & 1.29 & 967 & 1398 & 1.45 \\
\hline
\end{tabular}

Table 3: Peak value of acceleration and displacement response of each pier.

\begin{tabular}{lcccccc}
\hline Location & \multicolumn{2}{c}{ Pier 1\# } & \multicolumn{2}{c}{ Pier 2\# } & \multicolumn{2}{c}{ Pier 3\# } \\
Direction & Radial & Tangential & Radial & Tangential & Radial & Tangential \\
\hline Acceleration (gal) & 323.615 & 499.124 & 235.436 & 371.163 & 593.977 \\
Displacement (mm) & 10.434 & 19.204 & 7.1670 & 19.597 & 20.365 & 315.012 \\
Resultant displacement (mm) & & 21.855 & & 20.866 & 10.016 \\
\hline
\end{tabular}




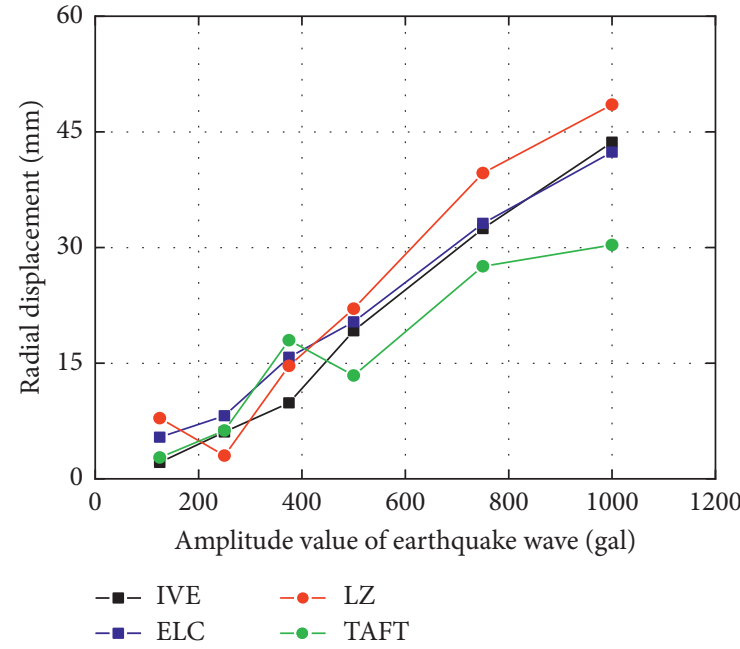

(a)

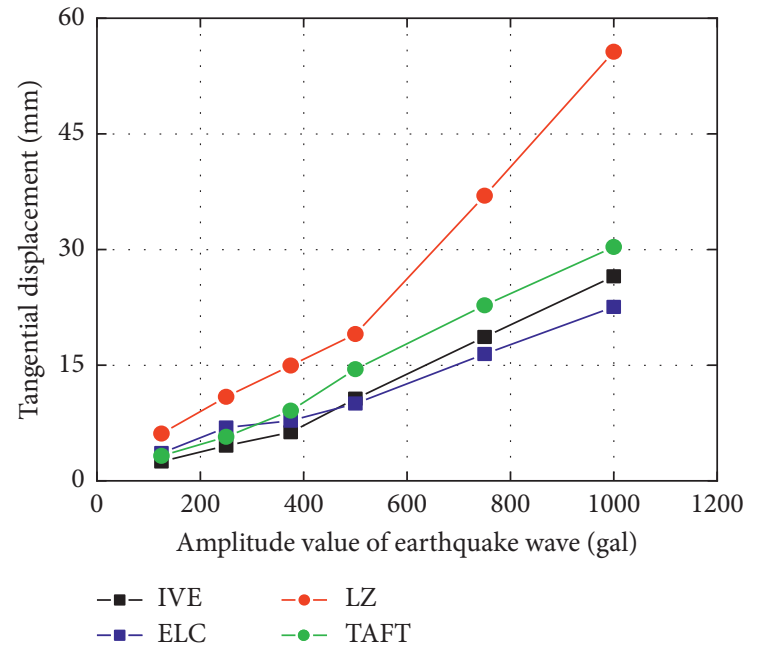

(b)

FIgURE 6: The relationship between displacement response and acceleration of pier 3\#. (a) Radial. (b) Tangential.

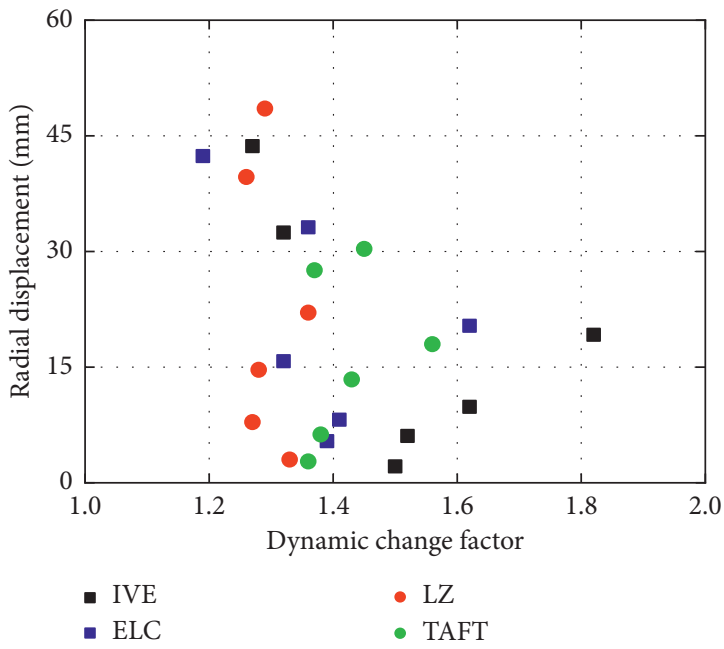

(a)

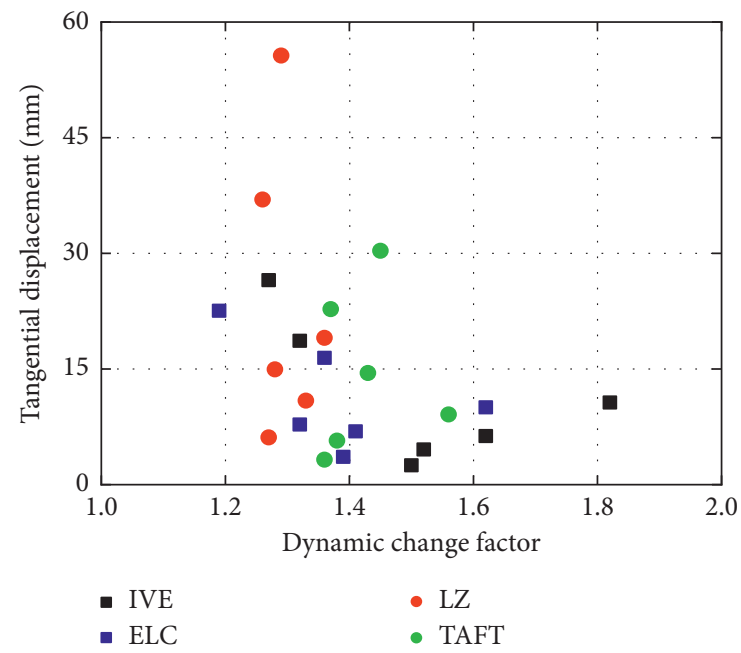

(b)

Figure 7: The relationship between displacement response and dynamic change factor of pier \#3. (a) Radial. (b) Tangential.

is due to excessive stress. This article only analyzes the strains at the bottom and middle of each pier under a representative El-Centro earthquake wave. The strain response of bridge pier is shown in Figure 8.

From Figure 8, the peak strain of pier 3\# is greater than pier $1 \#$ and pier 2\# under different acceleration peak inputs; it shows that considering the multi-point excitation results in an increase in the strain response of the piers. The maximum strain among the three piers is $1628 \mu \varepsilon$, all of which have not reached the yields strain of $1675 \mu \varepsilon$. The non-yielding steel bar of the bridge pier is due to the sliding isolation of the laminated rubber bearing between the girder and the pier; the inertia force of the girder under the earthquake cannot act on the pier, resulting in a small seismic load on the pier. 


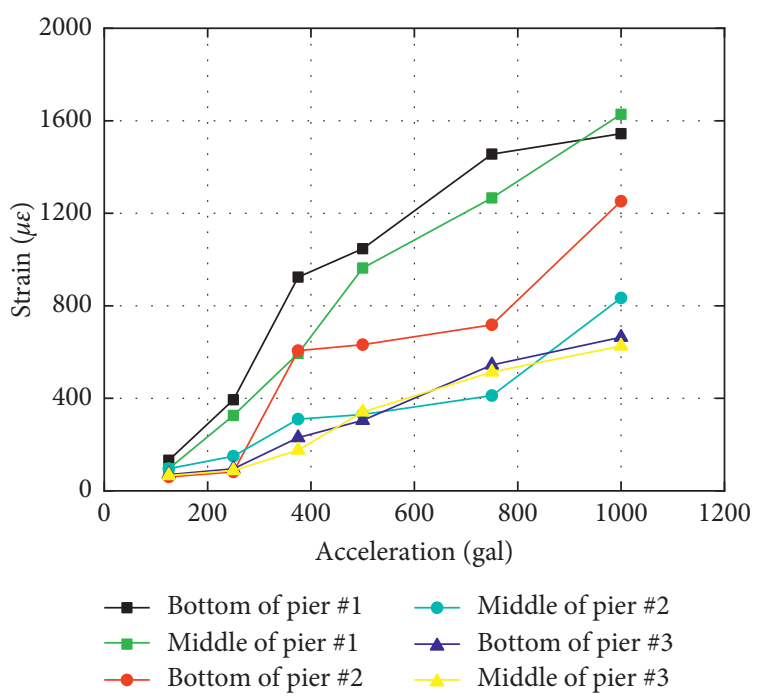

FIgURE 8: The strain response of bridge pier.

\section{Conclusion}

In this paper, the shaking table test of reinforced concrete high pier and small radius curves bridge with a scale ratio of $1 / 20$ was carried out, the seismic response law of the curved bridge under multi-point excitation was studied, and the following conclusions are obtained.

(1) Generally speaking, with the increase of seismic load level, the frequency of high pier and small radius curves bridge gradually decreases, and the damping ratio increases with the aggravation of the damage of structure.

(2) A clear working mechanism for the expansion device of shaking table is designed in this paper, which can effectively change the peak acceleration of seismic waves and realize the simulation of local terrain effect. It is feasible to complete the multi-point excitation test by a single shaking table.

(3) The differences of seismic wave between expansion device and shaking table show that different propagation law of seismic wave under the condition of the same site is not the same. Therefore, in the seismic design of high pier and small radius curved bridge, the effect of seismic wave characteristics on the supports of structure due to local terrain effects should be considered.

(4) After the amplification effect of local terrain effects on seismic waves, the seismic response of high pier and small radius curves bridge becomes more complicated. The displacement response of pier $3 \#$ is significantly increased compared with pier \#1, indicating that there are significant differences in the seismic demand of different piers after the local terrain effect is taken into account, and the seismic design should be calculated according to the seismic requirements of different piers.

(5) The strain response of high pier and small radius curves bridge shows that local terrain effects can increase the strain response piers. In addition, the frictional slip of bearings can effectively reduce the transfer of the inertia force of the girder to the bridge pier, making the actual seismic force of the bridge pier smaller and effective, so as to avoid the formation of the plastic hinge of the bridge pier.

\section{Data Availability}

The data used to support the findings of this study are available from the corresponding author upon request.

\section{Conflicts of Interest}

The authors declare that there are no conflicts of interest regarding the publication of this paper.

\section{Acknowledgments}

This project was supported by the Project of Chongqing Science and Technology Committee (cstc2018jscx-msybX0167), General Program of China Postdoctoral Science Foundation (2019M663442), Scientific and Technological Research Program of Chongqing Municipal Education Commission (KJQN202001216, KJQN201901219), Wanzhou District Science and Technology Innovation Project (Research and Application of Key Technologies for Earthquake Induced Safety of Small and Medium Span Beam Bridges in Mountainous Areas), and Chongqing Engineering Research Center of Disaster Prevention and Control for Banks and Structures in Three Gorges Reservoir Area (SXAPGC18ZDI02/03, SXAPGC19ZDI01). 


\section{References}

[1] M. L. Cheng, Q. N. Li, L. Yan, and J. H. Yin, "Experimental study on seismic response of irregular high pier curved Bridges under multi-point excitation," Journal of Vibration Engineering, vol. 29, pp. 880-887, 2016.

[2] L. C. Fan, Earthquake Resistance of Bridges, Tongji University Press, Shanghai, China, 1997.

[3] H. C. Gomez, P. J. Fanning, M. Q. Feng, and S. Lee, "Testing and long-term monitoring of a curved concrete box girder bridge," Engineering Structures, vol. 33, no. 10, pp. 2861-2869, 2011.

[4] L. Yan, Q. N. Li, J. H. Yin, C. Han, and M. L. Cheng, "Shaking table test of herringbone bridge under multi-dimensional earthquake excitation," Journal of Vibration and Shock, vol. 7, pp. 167-176, 2016.

[5] L. Yan, Q. Li, C. Han, H. Jiang, and J. P. Sun, "Shaking table tests of curved bridge considering bearing friction sliding isolation," Shock and Vibration, vol. 2016, Article ID 6245062, 14 pages, 2016.

[6] L. Yan and Q. N. Li, "Experimental study on Y-shaped bridge under 3-dimentional earthquake ground motions," KSCE Journal of Civil Engineering, vol. 21, pp. 2329-2337, 2017.

[7] D. Williams and W. Godden, "Seismic response of long curved bridge structures: experimental model studies," Earthquake Engineering and Structural Dynamics, vol. 7, no. 2, pp. 107-128, 1979.

[8] C. Nuti and I. Vanzi, "Influence of earthquake spatial variability on differential soil displacements and SDF system response," Earthquake Engineering and Structural Dynamics, vol. 34, pp. 1353-1374, 2005.

[9] J. B. Liu, "Effect of local irregular topography on ground motion of earthquake," Acta Seismologica Sinica, vol. 2, pp. 239-245, 1996.

[10] Z. Zhang, X. J. li, and R. Q. Lan, "Design and experimental research of vibration table for small radius curved bridge," Journal of Vibration and Shock, vol. 4, pp. 100-107, 2019.

[11] A. Lupoi, P. E. Pinto, and G. Monti, "The Seismic design of Bridges accounting for spatial variability of ground motion," Earthquake Engineering and Structural Dynamics, vol. 4, pp. 327-348, 2010.

[12] L. Wang, Seismic response analysis and shaking table test of long-span rigid frame bridges, $\mathrm{PhD}$ Thesis, Beijing Jiaotong University, Beijing, China, 2010.

[13] L. Wang, C. M. Zhao, and Z. F. Wang, "Seismic response analysis of long-span and high-pier Bridges considering topographic effects and multi-point excitation," China Civil Engineering Journal, vol. 13, pp. 55-58, 2006.

[14] G. H. Liu and X. Feng, "Seismic analysis of Bridges across v-shaped valleys: multi-point seismic simulation of $\mathrm{v}$-shaped sites with multilevel stratification and heterogeneous media," China Journal of Highway and Transport, vol. 12, pp. 150-158, 2017.

[15] G. H. Liu, X. Feng, and D. L. Jiang, "Failure mode of bridges under multi-support excitation in a V-shaped canyon with multi-layer topography," China Journal of Highway and Transport, vol. 8, pp. 101-113, 2019.

[16] W. Xie, L. M. Sun, and M. L. Lou, "Shaking table test on a pilesoil-cable-stayed bridge full model under multi-support excitations," Journal of Civil Engineering, vol. 52, pp. 83-93, 2019. 